\title{
Effectiveness of a Theory Based Comprehensive Sexual Education Program at a Baltimore City High School
}

Darlene Hinds

West Virginia University

Follow this and additional works at: https://researchrepository.wvu.edu/etd

\section{Recommended Citation}

Hinds, Darlene, "Effectiveness of a Theory Based Comprehensive Sexual Education Program at a Baltimore City High School" (2013). Graduate Theses, Dissertations, and Problem Reports. 4971.

https://researchrepository.wvu.edu/etd/4971

This Dissertation is protected by copyright and/or related rights. It has been brought to you by the The Research Repository @ WVU with permission from the rights-holder(s). You are free to use this Dissertation in any way that is permitted by the copyright and related rights legislation that applies to your use. For other uses you must obtain permission from the rights-holder(s) directly, unless additional rights are indicated by a Creative Commons license in the record and/ or on the work itself. This Dissertation has been accepted for inclusion in WVU Graduate Theses, Dissertations, and Problem Reports collection by an authorized administrator of The Research Repository @ WVU.

For more information, please contact researchrepository@mail.wvu.edu. 
Effectiveness of a Theory Based Comprehensive Sexual Education Program at a Baltimore City High School

Darlene Hinds, MSN, RN, CRNP, FNP-BC

Doctoral Capstone Project submitted to the School of Nursing at West Virginia University in partial fulfillment of the requirements for the degree of

Doctorate of Nursing Practice

Ilana Chertok, PhD, MSN, RN, IBCLC, Chair Lorretta Jemmott, PhD, FAAN, RN Mr. Graham

Department of Nursing

Morgantown, West Virginia 2013

Keywords: abstinence, adolescent, comprehensive sex education, sexually transmitted infections, teen pregnancy

Copyright 2013 Darlene V. Hinds 


\author{
ABSTRACT \\ Effectiveness of a Theory Based Comprehensive Sexual Education Program \\ at a Baltimore City High School \\ Darlene V. Hinds
}

\title{
Background
}

Sexual activity among adolescents can have lifelong consequences including teen pregnancy and sexually transmitted infections. The Youth Risk Behavior Surveillance Survey (YRBSS), reported $13.8 \%$ of high school students grades $9-12$ admitted to having intercourse with four or more people and $34.2 \%$ report being sexually active (CDC, 2010b). Baltimore City has disproportionately high rates related to teen pregnancy, chlamydia and gonorrhea when compared to national statistics. In 2006, the rate of teen births among girls ages 15-19 in Baltimore City was 66.4 per 1,000, compared to Maryland's teen birth rate of 34.4 per 1,000 (Maryland Department of Health and Mental Hygiene (DHMH), 2007). Baltimore City's rates were also higher than the national teen pregnancy birth rate of 42.5 per 1,000 (CDC, 2010).

Objectives

The purpose of this project was to assess the effectiveness of comprehensive sexual education program among Baltimore City high school students. The primary goals of the program were to increase sexual self-efficacy, the knowledge of risks associated with sexual activity, and the use of contraceptives that decrease pregnancy and STIs following a 16 lesson intervention.

Design

The Reducing the Risk comprehensive sexual education program was taught bi-weekly. This study used a one group pretest-posttest quasi experimental design. There were three instruments used to measure effectiveness. The first was the Reducing the Risk Knowledge Survey, the second was the CDC 2011 Youth Risk Behavior Survey (YRBS) and the third was the Teen Attitude Pregnancy Scale (TAPS). The participants were 12th grade students attending a high school in Baltimore city, Maryland.

Results

A statistically significant difference was present in the knowledge score from the preintervention phase to the postintervention of $14.1 \pm 2.7(\mathrm{t}=-5.854, \mathrm{df}=36, \mathrm{p}<0.001)$ and self efficacy pretest scores of $13.3 \pm 3.5$ to the posttest score of $16.5 \pm 3.1(\mathrm{t}=-4.9, \mathrm{df}=36, \mathrm{p}<0.001)$. No significant change was noted however in contraceptive use.

Conclusion

A comprehensive sexual education program can be effective at increasing the knowledge of risks associated with sexual behavior and sexual self efficacy. 


\section{ACKNOWLEDGMENTS}

I would like to acknowledge and thank the following:

My capstone chair, Dr. Ilana Chertok and committee members, Dr Lorretta Jemmott and Mr. Ralph

Graham for their support and guidance.

Dr. Marcella Copes, Dr. Joan Tilghman, Dr. Tracey Murray for motivating me to pursue my doctoral degree and the support and mentorship they have provided during the last three years.

My family for their never ending support and words of encouragement.

To JaMarr for your love, support and patience during those late nights and doubtful times.

Finally and most importantly, to God for sustaining me during this journey. 


\section{Table of Contents}

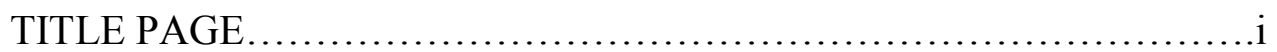

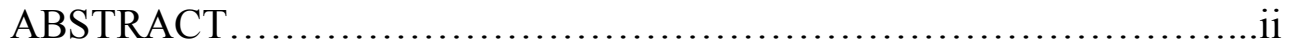

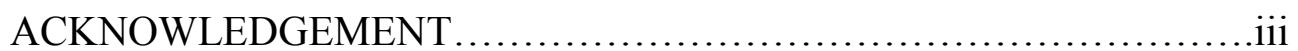

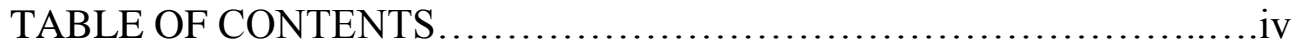

CHAPTER I: INTRODUCTION .......................................

BACKGROUND AND SIGNIFICANCE......................1

THEORECTICAL FRAMEWORK ............................. 3

CHAPTER II: LITERATURE REVIEW AND SYNTHESIS.............6

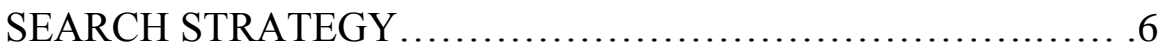

REVIEW OF LITERATURE................................6

SYNTHESIS ...............................................11

PROJECT'S CONGRUENCE OF STRATEGIC PLAN............12

PROJECT OBJECTIVES....................................13

CHAPTER III: METHODOLOGY .................................. 16

PROJECT DESIGN ........................................ 16

RESOURCES........................................... 16

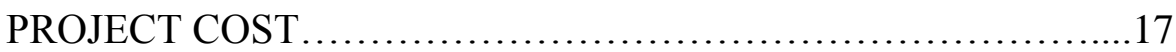

PROCEDURE............................................. 17

EVALUATION PLAN AND INSTRUMENTS .................. 18

CHAPTER IV: RESULTS.......................................21

CHARACTERISTICS OF THE SAMPLE .......................21 
PROJECT RESULTS........................................21

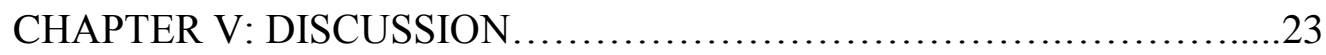

CONGRUENCE WITH THEORETICAL FRAMEWORK...........23

BARRIERS AND RECOMMENDATIONS.....................25

CONCLUSION .............................................26

PERSONAL GOALS ......................................27

APPENDIX A: LETTER OF SUPPORT ..............................28

APPENDIX B: APPROVAL TO USE T.A.P.S ............................ 30

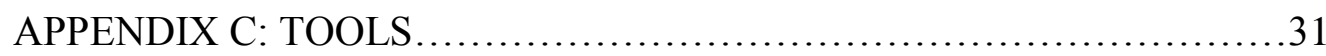

FIGURE 1: EXPLANATION OF CLASSES $\ldots \ldots \ldots \ldots \ldots \ldots \ldots \ldots \ldots \ldots \ldots . \ldots . \ldots \ldots$

TABLE 1: CDC GROWTH CHART BOYS $\ldots \ldots . . . \ldots \ldots \ldots \ldots \ldots \ldots \ldots \ldots \ldots . . . \ldots 1$

TABLE 2: USE OF CONTRACEPTIVES BY GENDER .....................42

TABLE 3: SELF EFFICACY AND KNOWLEDGE .....................43

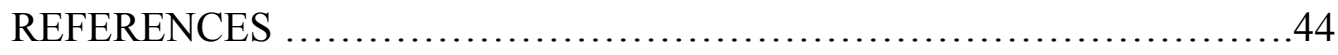




\section{Chapter I: Introduction \\ Background and Significance}

\section{Statement of the Problem}

Baltimore City's rates of teen pregnancy and sexually transmitted infections (STIs) are higher than Maryland and national rates. Prevention of these consequences associated with sexual behavior can be achieved, in part, with education. Presently, Baltimore City Public Schools do not have a standardized curriculum that addresses sexual behavior. There is a need for a comprehensive sexual education intervention in Baltimore City schools to increase knowledge of risks associated with sexual behavior and methods of prevention.

\section{Epidemiology of the Problem}

The National Survey of Family Growth 2006-2008, reported that 27.7\% of female participants $(n=5,810)$ and $28.8 \%$ of male participants $(n=6,643)$ reported having engaged in their first sexual intercourse between the ages of 15-17 (Center for Disease Control (CDC), 2010). The Youth Risk Behavior Surveillance Survey (YRBSS), reported $13.8 \%$ of high school students grades 9-12 admitted to having intercourse with four or more people and $34.2 \%$ report being sexually active (CDC, 2010b). According to the Guttmacher Institute (2010), in 2006 the

pregnancy rate among teens ages $15-19$ was 71.5 per 1,000 . The CDC (2011) reported that $39 \%$ of newly diagnosed HIV infections were young people ages $13-29$. Furthermore, 65\% or 5,404 of newly diagnosed HIV infections were to African Americans ages 13-24 (CDC, 2011).

\section{Consequences of Sexual Behavior}

Teen pregnancy financially impacts the community, the teen, and the future child. The National Campaign to Prevent Teen Pregnancy (2011) reported at least \$10.9 billion dollars are spent by taxpayers every year because of teen pregnancy. The CDC (2010c) has reported 24,000 women in the United States (U.S.) become infertile as a result of STIs. Adolescent girls have the 
highest incidences of chlamydia and gonorrhea when compared to every other age group studied (CDC, 2008). In 2009, a total of 1,244,810 were diagnosed with chlamydia, 430,255 were teens ages 15-19; a rate of 1999.9/100,000 (CDC, 2010c). The CDC (2010c) also identified that in 2009 , there were 301,174 cases of gonorrhea reported, 87,221 of those cases were teens ages 15 19; a rate of 405.4/100,000.

\section{Baltimore City}

Baltimore City has disproportionately high rates related to teen pregnancy, chlamydia and gonorrhea when compared to national statistics. In 2006, the rate of teen births among girls ages 15-19 in Baltimore City was 66.4 per 1,000, compared to Maryland's teen birth rate of 34.4 per 1,000 (Maryland Department of Health and Mental Hygiene (DHMH), 2007). Baltimore City's rates were also higher than the national teen pregnancy birth rate of 42.5 per 1,000 (CDC, 2010). According to the 2008 surveillance report (CDC, 2009), the U.S. reported 379,416 cases of chlamydia, a rate of $1,766.9$ per 100,000 for males and females ages $15-19$. In that same year, Maryland reported 120.5/100,000 cases while Baltimore City had the highest incidence with 474.4 per 100,000 .

Comprehensive education programs provide education aimed at reducing risky sexual behavior utilizing methods to increase knowledge of the consequences of behavior, contraceptive use and sexual self-efficacy. Numerous research studies have been completed assessing comprehensive education methods to prevent increased incidence of pregnancy and STIs in the adolescent population (Origanje et al., 2009; Robin et al., 2004).

\section{Research Question}

The research question proposed by this author is: Is comprehensive sexual education an effective method of increasing self-efficacy, knowledge of risks associated with sexual activity, 
and use of contraceptives that decrease pregnancy and STIs among adolescents attending a high school in Baltimore City, Maryland?

\section{Theoretical Framework}

Research on comprehensive sexual education programs for adolescents has shown the use of various theoretical frameworks. The Health Belief Model was the theory chosen to assist in successful achievement of the aforementioned outcomes.

\section{Key Elements of the Health Belief Model}

The Health Belief Model (HBM) focuses on attitudes and beliefs of the individual to predict and explain health behaviors (Rosenstock, Stretcher, \& Becker, 1988). The concepts of the theory are perceived susceptibility, perceived severity, perceived benefits, perceived barriers (perceived cost), cues to action, and self-efficacy. Perceived susceptibility is the perception of vulnerability to a condition, perceived severity is the belief of the seriousness of a condition, and perceived barriers is the belief of negative results when adhering to the prescribed action. Perceived barriers also relates to the perceived cost of adhering to the behavior change. Cues to action encourage the client to begin to change his or her behavior. Self-efficacy is the client's belief that he or she will be able to take action to modify his or her behavior. The HBM was chosen because it uses the method of education and motivation to attain the desired change. Hall (2011) wrote the adaptability of the HBM, and the holistic structure of the theory allows for its application in various programs including family planning and contraceptive education.

\section{Articulation with Clinical Problem}

Application and success of the HBM in a program developed to prevent sexually risky behavior is based primarily on the concepts of susceptibility and severity (Hiltabiddle, 1996). Hiltabiddle (1996) writes, "To change the behavior of adolescents, programs must address the 
perception of risk" (p. 63). Downing-Matibag (2009) performed a qualitative study that used the HBM to study the risky sexual behaviors of 71 college students. According to DowningMatibag (2009), a majority of the students in the study were unaware that their behavior placed them at risk for STIs.

Success of the comprehensive education program was measured by increased selfefficacy, increased knowledge of risks associated with sexual activity, and self-report of increased use of contraceptives that decrease pregnancy and STIs. Students in the program received weekly 45 minute lessons during their health class. Buy in from the participants had to occur early in the intervention. It was imperative for the adolescents to believe that they were at risk for pregnancy and STIs (Perceived Susceptibility), and become aware of the seriousness of the potential outcomes of engaging in sexual activity (Perceived Severity). The challenge of the student realizing his or her susceptibility was met with statistics, case studies and role playing. The incidence of HIV diagnoses, STIs, and teen pregnancy for their age group were discussed. The severity of the consequences of risky sexual behavior was discussed. The potential consequences of infertility, morbidity and mortality associated with STIs were emphasized. The acceptance of possible risk and the comprehension of severity will lead them to seek preventive measures. After participants were made aware of the risk, education regarding the benefits of abstinence, the use of condoms, and decreasing risky behaviors was taught (perceived benefit). The benefits were presented in many ways including discussion with supporting statistics, role playing and individual and group activities. The perceived barriers to change behavior discussed by the students included embarrassment to discuss contraceptive use and sexual history with partners or misconceptions such as the idea that there is a lack of feeling with condom use, the belief that their partner is disease free, and the thought that everyone else is doing it. The 
potential cost of contraception can also be a barrier to change. A list of locations that dispense free contraception was provided to the students. The intervention provided the participants with methods to discuss how to say no, wearing condoms and sexual history with potential partners. Cues to action were the weekly educational sessions with discussion and practical skills sessions in using contraceptives and in having discussions with partners about contraception use. The change in behavior occurred (reduction of risky sexual behaviors) if the adolescent believed in his or her ability to perform the behaviors needed for the change such as correct application of a condom or the ability to have the conversation about contraception with a partner (Saunders, 2005). 


\section{Chapter II: Literature Review and Synthesis}

\section{Project Description}

\section{Search Strategy}

A search was conducted through the databases Academic Search Complete, CINAHL, PubMED, National Guidance Clearinghouse and the Cochrane Library. The inclusion criteria for this search included articles published in the English language within the ten year span from 20002010. The keywords for the search were: adolescent pregnancy, teenage pregnancy, STI/STDs, teenage pregnancy prevention programs, teenage pregnancy intervention programs, and STI/STD intervention programs. The initial search using the keywords adolescent pregnancy prevention resulted in 1,579 hits. The search was then narrowed using the phrases teen pregnancy intervention program, sexual self-efficacy in the adolescent and risky sexual behavior in the adolescent. CINAHL's "smart text" feature and snowballing were also used to find literature. Articles were excluded if they did not include the key terms of either adolescent/teen pregnancy prevention or adolescent/teen STI/STD prevention. Ten articles met the criteria for inclusion including: one practice guideline, two systematic reviews (SR) (Origanje et al., 2009; Robin et al., 2004), three randomized control trials (RCTs) (Jemmott, Jemmott, Fong \& Morales, 2010; Jemmott, Jemmott, Braver \& Fong, 2005; Dolcini, Harper, Boyer \& Pollack, 2010), and one quasi-experimental study (Roberto et al., 2007).

\section{Review of the Literature}

The practice guideline was appraised using the AGREE instrument (Agree Research Trust, 2006) and the SRs (Origanje et al., 2009; Robin, et al., 2004) and the RCTs (Dolcini et al., 2010; Jemmott et al., 2005 and Jemmott et al., 2010) were critically appraised using the appropriate form from the Scottish Intercollegiate Guideline Network (SIGN). The Quasi- 
experimental study (Roberto et al. 2007) was appraised using a quantitative worksheet (Larrabee, 2009).

The Sexuality Information and Education Council of the United States (SIECUS) Comprehensive Sexual Education Guidelines (2004) were written to assist in development and evaluation of comprehensive sexual education programs. The objectives of the guideline are clearly stated at the beginning of the document. Target users of the document are identified in the purpose of the guideline. The guidelines highlight overall concepts that should be found in effective sexual education programs. The target populations of grades K-12 are identified and age appropriate applications of each concept are thoroughly discussed. Checklists are provided to ascertain whether messages were clear, skills objectives were met and to assist with potential teaching strategies and cultural sensitivity. The guidelines also provide various resources to help facilitators including books, websites, organizations, and research articles. The guidelines did not include information regarding the databases or methods used to collect research for development.

Origanje et al.'s systematic review (2009) evaluated the effectiveness of interventions on adolescent teen pregnancy. Secondary outcomes included changes in knowledge and attitudes about the risk of unintended pregnancies. The study describes an extensive search of the databases regardless of language or publication status, contact with individual researchers, national and international research institutes and organizations. A total of 41 studies met inclusion criteria of randomized controlled trials with clear evidence of concealment of allocation and blinding (or no influence on outcomes if no blinding existed) and male and female participants aged 10-19. Results of the research showed a decreased risk of pregnancy amongst adolescent who attend programs that implement multiple interventions. Strengths of the 
systematic review include the randomized control design, the number of included studies (41) and participants $(95,662)$, and detailed description of inclusion criteria. Limitations of the review include: the use of self-report data for the majority of the studies included, heterogeneity in the program designs and implementation and lack of clear comparison between the studies. Robin et al. (2004) conducted a systematic review to identify behavioral interventions that proved effective at reducing incidences of HIV, STD and teen pregnancy among adolescents. Twenty four articles met the criteria for inclusion. Studies included used random assignment or matched control groups using a quasi-experimental design. If inequalities were noted during analysis, studies were included if the researchers controlled for the differences statistically. Studies were included: if they had more than 16 participants per condition, followed participants for at least four weeks after the end of the intervention or had immediate pre and post tests for interventions lasting four months or longer, and had attrition rates of less than $40 \%$ at follow up four weeks after the end of the intervention. An additional strength of the review was the clear description of each article including population, design, attrition and limitations in table format. Four interventions were identified as having an impact on the success of a program: program duration and intensity, assumptions regarding participant's exposure to prior and concurrent programs, the amount of focus placed on skills for reducing sexual risk behaviors, and training for the facilitators. Literature reviews and economic evaluations were not included. Weakness of the review included that the search was limited to articles published in English and heterogeneity among the various interventions related to participants, design and implementation.

Dolcini et al. (2010) used the randomized control trial design to evaluate the effectiveness of a friendship based HIV/STD prevention intervention developed specifically for urban African 
American females living in communities with high prevalence of STIs. Two neighborhoods in San Francisco were randomly assigned to an experimental group and two were assigned to the control group. A total of 264 females ages 14-21 participated and attended a five hour HIV/STI intervention. A pre-intervention baseline questionnaire and two post-intervention questionnaires were used three to four months after the completion of the intervention. The outcomes of the study showed a decrease in risky sexual behavior $(\mathrm{OR}=0.39, \mathrm{p}=.01,95 \% \mathrm{CI}=0.18-0.86)$, fewer sexual partners $(\mathrm{OR}=0.22, \mathrm{p}=.04,95 \% \mathrm{CI}=0.05-0.97)$, and higher reports of HIV testing $(\mathrm{OR}=7.43, \mathrm{p}=.05,95 \% \mathrm{CI}=0.95-58.33)$ in the experimental vs. the control group (Dolcini et al., 2010). Information regarding the method for inclusion and exclusion and the five hour intervention were described in detail. A limitation of the study was that some of the participants lived in the control community and participated in the treatment group, contributing to a potential risk of spillover bias. Furthermore, the post questionnaire was administered only three months following the intervention and the outcomes were measured by self-reported sexual behavior and STI testing.

Jemmott et al. (2010) examined the effectiveness of a Community Based Organization (CBO) facilitated HIV/STD risk reduction intervention program, for adolescents using a cluster randomized control design. The primary proposed outcome of the intervention was consistent condom usage in the three months prior to each follow-up. A total of 1,558 participants completed the entire study including the 3, 6, and 12 month follow up. The results of the research showed participants in the intervention were more likely to report consistent condom use $(\mathrm{OR}=1.29 ; 95 \% \mathrm{CI}=1.06,1.84)$ than were participants from the control group. Participants in the intervention also reported more instances of condom protected intercourse ( $\beta=0.06 ; 95 \% \mathrm{CI}=0.00,0.12)$ when compared to the control group. The research clearly defines 
the criteria for inclusion and exclusion of participants. The strengths of the study included the use of a computer generated randomized assignment, blinding of participants to the intervention condition prior to enrollment, inclusion of 88 Community Based Organizations from two states and were retained through follow-up, the large sample size, and appropriate length of follow-up. The research included CBO's that worked with African American adolescents. This may be viewed as a possible limitation of the study when replication among various populations is attempted.

Another study measured the efficacy of a skill-based HIV/STD risk-reduction intervention among African American and Latino girls. Jemmott et al. (2005) performed a randomized controlled trial with 682 participants divided into one of three interventions. The three interventions included an information and skills based HIV/STD intervention, an information only session and a health promotion control intervention with information unrelated to sexual behavior. The results of the research include at the twelve month follow-up, less frequent unprotected sexual intercourse among skill based intervention participants versus the health promotion control intervention $(\mathrm{d}=0.28 ; \mathrm{P}=.002)$ or the information based intervention $(\mathrm{d}=0.19 ; \mathrm{P}=.033)$. Also reported in the skills based intervention at the twelve month follow up were fewer sexual partners and decreased acts of intercourse while intoxicated at the twelve month follow up. There was also an increase in knowledge about HIV/STD $(\mathrm{d}=0.62 ; \mathrm{P}=<.001)$ and condom use $(\mathrm{d}=0.59 ; \mathrm{P}<.001)$ among the skills intervention participants at the twelve month follow up. Strengths of the study include the use of a computer generated randomized control design, a single intervention was used (ensuring $100 \%$ attendance), attrition was low and biologically confirmed outcomes were used in addition to self-reporting. 
Roberto et al. (2007) completed a quasi-experimental study to evaluate the effectiveness of a computer and Internet based health communication intervention designed to prevent pregnancy, STIs and HIV in rural adolescents. Participants were 887 tenth graders enrolled in nine rural public high schools. The treatment group demonstrated significantly greater knowledge and condom self-efficacy, had significantly more favorable attitudes toward waiting to have sex, and perceived significantly greater susceptibility to HIV than the control group. The intervention was described in detail and included knowledge about sex, condom self- efficacy, attitudes toward waiting to have sex, perceived susceptibility to pregnancy, STDs, HIV, and pregnancy. The identified strengths of the study included: detailed description of the program, use of the quasi experimental design, length of the study and the use of process evaluation to ensure correct implementation of the program.

\section{Synthesis}

The evaluation of the research (Origanje et al., 2009; Robin et al., 2004; Jemmott et al., 2010, Jemmott et al., 2005; Dolcini et al., 2010; Roberto et al., 2007 and SIECUS guidelines support the use of comprehensive sexual education programs to reduce the incidence of STIs and pregnancy among the adolescent. The systematic reviews (Origanje et al., 2009; Robin et al., 2004) provide strong evidence that comprehensive prevention interventions for adolescents decrease the incidence of STIs, teenage pregnancy and sexual risk behavior. Homogeneity was present across the studies related to the use of some form of education intervention, however some of the studies included skills interventions. Heterogeneity was present across some of the studies related to location of the intervention (CBOs, schools, internet), race, age and gender. Consideration of these differences should be taken into account prior to the replication of these studies. The use of self-reporting is a weakness that was present throughout the studies, although 
the nature of the research including questions about past and present sexual activity and use of contraception require self-report from the participants. Origanje et al. (2009) states there is bias associated with self-reported data as there is an inclination for the participants to choose the answer associated with healthy behavior. Two of the articles (Jemmott et al., 2005; Jemmott et al., 2010), implemented additional measures to assist in increasing the validity of self-reporting including reporting over brief periods, the use of calendars of the time period and proctors unknown to the participants. The longest postintervention time was one year (Jemmott et al., 2005; Jemmott et al., 2010). Longer follow up times are needed to determine the long term effectiveness of the interventions. The studies did not mention the cost of implementation of the various programs. Further research is needed on the type of content that is most effective (skill based, knowledge and skill based, theory driven, gender focused), the method of delivery (internet or face to face), length of the program and time period for follow up.

\section{Congruence of Organizations Strategic Plan to Project}

In Baltimore, Maryland the recommendation was made in 2010, by a committee designed by the Health Department made up of youth groups, Johns Hopkins Urban Health Institute and the Center for Adolescent Health to develop a "complex and comprehensive approach to reduce teen pregnancy, and more specifically, teen births among Baltimore youth" (Baltimore City Health Department, 2010,pg. 7). A portion of this plan suggested that all middle and high schools in the public school system provided evidenced based prevention programs. The goal of Reducing the Risk is to "affect knowledge, beliefs, values and intentions related to abstinence, unprotected sexual activity, unintended teen pregnancy and STD contraction of high school students" (Department of Health and Human Services, 2010). The objectives of the Reducing the 
Risk comprehensive sexual education program is in alignment with the Baltimore City Health Department goals for teen pregnancy.

\section{Project Objectives}

The outcomes to be achieved and evaluated as part of this capstone project were:

To increase self-efficacy among adolescents who complete a 16 lesson education session as evidenced by a change from the pretest to post test scores on the Teen Attitude Pregnancy Scale (TAPS) (Somers, Johnson \& Sawilowsky, 2002).

To increase knowledge of risks associated with sexual activity among adolescents who complete a 16 lesson education session as evidenced by a change from the pretest to posttest scores on the Reducing the Risk - Knowledge Survey (ETR Associates, 2010).

To increase the use of contraceptives as a health behavior that decreases pregnancy and STIs among adolescents who complete a 16 lesson education session as evidenced by a change from the pretest to post test scores on the Youth Risk Behavior Surveillance Survey Questionnaire (Centers for Disease Control and Prevention, 2011).

\section{Self-Efficacy}

a. Implement a comprehensive sexual education program aimed at increasing sexual self-efficacy among senior high school students in Baltimore.

b. Administer a pretest prior to initiation and posttest specifically measuring selfefficacy six weeks following the completion of the comprehensive sex education program. The posttest results should demonstrate increased sexual efficacy among the participants.

c. Implement education that includes instruction on self-efficacy through role playing and group discussion to be effective. 
d. An increase in self-efficacy will be noted from pretest to posttest. The posttest will be given approximately six weeks after the program is completed.

2. Knowledge of Risks Associated with Sexual Behavior

a. Implement a comprehensive sexual education program that utilizes lectures, role playing, group discussions, posters and handouts aimed at increasing knowledge of risks associated with intercourse among senior high school.

b. Administer a pretest prior to initiation and post-test six specifically measuring knowledge six weeks following the completion of the comprehensive sex education program. The posttest results should demonstrate increased knowledge related to the consequences of sexual behavior including teen pregnancy, HIV and STIs.

c. Implement the evidence based comprehensive educational program that will demonstrate an increase in knowledge among high school participants.

d. Evaluate the knowledge scores at baseline and at 6 weeks postintervention to determine if there is an increase in knowledge related to risks associated with sexual intercourse from pretest to posttest.

3. Use of Contraceptives that Decrease Pregnancy and STIs

a. Implement a comprehensive sexual education program aimed at increasing knowledge about contraceptives that decrease pregnancy and STI's among senior high school students, by utilizing teaching and return demonstration to instruct students on the proper use of contraceptives.

b. Administer a pretest prior to initiation and posttest specifically measuring self-efficacy six weeks following the completion of the comprehensive sex 
education program. The posttest results should demonstrate increased knowledge related to the consequences of sexual behavior including teen pregnancy, HIV and STIs.

c. Implement the evidence based comprehensive educational program that will demonstrate an increase in knowledge about contraceptives that decrease pregnancy and sexually transmitted infections among high school participants.

d. Evaluate the knowledge scores at baseline and at 6 weeks postintervention to determine if there is an increase in knowledge and use of contraceptives that decrease pregnancy and sexually transmitted infections from pretest and posttest. 


\section{Chapter III: Methodology}

\section{Project Design}

This capstone project utilized a quasi-experimental one group pretest, posttest design. The Reducing the Risk Comprehensive Sexual Education program (ETR Associates, 2010) was implemented at Baltimore high school. This program included sixteen 45 minute lessons to be taught bi-weekly. The lesson topics included abstinence; avoiding high risk situations; getting, knowing and discussing contraception; preventing HIV and other STIs and skills integration. The teaching modalities utilized were lectures, discussion, research and role playing. The Reducing the Risk program has been chosen by the U.S. Department of Health and Human Services, Office of Adolescent Health as an effective evidence based program. Furthermore, research has shown that the program, is effective at delaying the onset of intercourse, reducing the rates of unprotected intercourse, increasing the knowledge of contraception, and increasing the use of condoms (Kirby, Barth, Leland \& Fetro, 1991; Hubard, Giese, Rainey, 1998; Zimmerman et al., 2008).

Internal stakeholders were senior high school students, parents of the students participating in the project, the high school faculty and staff, and the Baltimore City Public School System. External stakeholders included: the high school neighborhood community, Baltimore City Health Department and other schools in the BCPSS or Baltimore County Public School System who may consider initiating a comprehensive sexual education program, following the outcome of this project.

\section{Resources}

A formal letter of support was received from the principal of the high school (Appendix A). The classroom and audiovisual equipment were provided. The Reducing the Risk program 
is a total kit that includes workbooks, handouts and posters. Every student received their own materials and no cost was associated with duplication. The implementation of this project is being completed by the author consequently, there is no cost associated with facilitating the program. However, if future replication is considered, the facilitator will complete 12 hours of instruction at the end of the program.

The complete set of Reducing the Risk including the cost of online training, lesson plans, posters and workbooks for 45 students cost $\$ 834.99$ which was funded by the author.

\section{Procedure}

Following approval from West Virginia University (WVU) Institutional Review Board (IRB) and Baltimore City Public School System, the program was purchased. In November 2012, this author met with Mr. Graham, the athletic director and health teacher to review the content of the program and develop a timeline to include meeting with the parents/guardians of potential participants, distribution and retrieval of consent/assent forms and scheduled days of implementation. The intervention began in February 2013 after retrieval of the consent and assent forms. Prior to the first day of class this author met with the students to discuss the program and address any concerns or questions the students had. The students completed the pretest on the first day. Each student then randomly picked a number which was used to identify the workbook they were given to use during the intervention.

The 16 lessons in the program were taught during 90 minute sessions 1 - 2 times a week. The curriculum was outlined as follows:

1. Prior to Class 1 Initiating Reducing the Risk

2. Class 1A Abstinence, Sex and Protection: Pregnancy Prevention Emphasis Class 1B Abstinence, Sex and Protection: HIV Prevention Emphasis 
3. Class 2 Abstinence: Not Having Sex

4. Class 3 Refusals

5. Class 4 Using Refusal Skills

6. Class 5 Delay Tactics

7. Class 6 Avoiding High-Risk Situations

8. Class 7 Getting and Using Protection-I

9. Class 8 Getting and Using Protection-II

10. Class 9 Knowing and Talking About Protection: Skills Integration-I

11. Class 10 Skills Integration-II

12. Class 11 Skills Integration-III

13. Class 12 Preventing HIV and Other STDs

14. Class 13 HIV Risk Behaviors

15. Class 14 Implementing Protection from STD and Pregnancy

16. Class 15 Sticking with Abstinence and Protection

17. Class 16 Skills Integration - IV

Every class session the workbooks were redistributed. Each class had different activities to allow the student to participate. These activities included role playing, skits, group and individual workbook assignments. Figure 1 describes the topics and main content of each of the class sessions. After cessation of the comprehensive sex education classes, the senior students did not receive any other sex education at the school. The posttest was given in May 2013.

\section{Evaluation Plan}

Evaluation of the effectiveness after implementation of the comprehensive sexual education program among high school senior students at single school was measured using three 
tools that measure sexual self-efficacy, knowledge of sexual risks associated with sexual behavior, and the use of contraceptives. The three tools, when combined, totaled 37 questions.

The Reducing the Risk Student Knowledge Survey was utilized to test students’ knowledge of correct condom application, methods of contraception and risk for and prevention of STIs. Responses used a three point scale with options for true, false, or not sure. The pretest and posttest scores were measured using a paired sample t-test to examine mean differences in knowledge before and after the intervention.

The second tool is the CDC 2011 Youth Risk Behavior Survey (YRBS). The portion of the survey used is specifically designed for sexual behavior. Questions in this survey are related to the use of contraceptives and incidences of sexual behavior. Answers from the pretest were compared to the six week post intervention test and McNemar's test was used to determine if an increase in the use of contraceptives was present. An increase in the use of contraception is the expected outcome. According to the CDC (2004) reliability and validity of the survey was tested via a two test reliability study. The tool is appropriate for students at an eighth grade level or higher (CDC, 2004). Approximately $75 \%$ of the items had a substantial or higher reliability $(\mathrm{kappa}=61 \%-100 \%)$. Furthermore, "no statistically significant differences were noted between the prevalence estimates for the first and second times that the questionnaire was administered" (CDC, 2004, pg. 7). The CDC (2004) also noted self-reports are influenced by cognitive and situational factors, however, "these factors do not threaten the validity of self-reports of each type of behavior equally" (pg. 7).

The third tool is the Teen Attitude Pregnancy Scale (TAPS). TAPS was developed as a method to evaluate the effectiveness of teen pregnancy prevention programs. Four categories were used: future orientation, realism about child rearing, sexual self- efficacy and personal 
intentions. This tool will be used to measure self-efficacy among the participants. Responses used a five point scale of very unsure, somewhat unsure, undecided, somewhat sure and very sure. According to Somers, Johnson, Sawilosky (2002), total scale reliability is 0.73 and the subscales range from 0.68 to 0.82 , which is considered acceptable. The expected outcome is an increase in posttest scores demonstrating increased self-efficacy. A paired sample t-test will be used to compare the means of the pretest and posttest scores. 


\section{Chapter IV: Results}

\section{Results}

A total of 38 students out of a possible 39 participated in the pretest survey and intervention and 37 completed the postintervention survey. The ages of the students were between $17-18$ years old with a mean age of 17.5 . $68 \%$ were female, $32 \%$ were male and $100 \%$ were African American. The mean age of onset of intercourse was 15 and $71 \%$ of the students reported that they had intercourse prior to the initiation of the intervention.

To assess whether there was an increase in the behavior of contraceptive use before and after the intervention, a McNemar's test was conducted. No statistically significant difference was noted after the intervention in the rate of students who reported using condoms and the method used to prevent pregnancy. At pretest, 21 students or $77.8 \%$ used a condom the last time they had intercourse, at posttest 20 students or $74.1 \%$ used a condom (Table 1). There were also no significant differences when the McNemar's tests were conducted separately for each gender (Table 2).

To determine statistical significance between the pretest and posttest knowledge surveys, the frequency of each response was calculated and a paired samples t-test was conducted. The Reducing the Risk Knowledge Survey showed a significant increase in the score of $10.7 \pm 2.4$ from the preintervention phase to the postintervention score of $14.1 \pm 2.7(t=-5.854, \mathrm{df}=36$, $\mathrm{p}<0.001$ ) (Table 3). In the knowledge survey the rate of answering the question related to the appropriate way to put on a condom increased from pretest to posttest (39.5\% correct vs. $70.3 \%$ ). Another question regarding the requirement of parental consent to get tested and treated for an STI at a clinic also increased (15.7\% vs. $70.3 \%)$. The use of hormonal birth control as a method to either prevent pregnancy or pregnancy and STI/HIV was also measured (65.8\% vs. 83.8\%). 
The mean difference between the pretest and posttest self-efficacy survey scores was measured using a paired samples t-test. There was a statistically significant increase from the pretest scores of $13.3 \pm 3.5$ out of a total possible score of 20 to the posttest score of $16.5 \pm 3.1(t=-$ 4.9, $\mathrm{df}=36, \mathrm{p}<0.001$ ) on the self-efficacy survey (Table 3 ). In the sexual self efficacy questionnaire 3 out of the 4 questions yielded high differences between the pretest and the posttest. One question asked how sure the participant was in being able to say no if they wanted to have sex but had no birth control. The second question asked how sure they were that they would always use birth control. The last question asked how sure they were they could say no if their partner wanted to have intercourse and they did not want to have intercourse. The scores for very sure were $21 \%$ vs. $62 \%, 16 \%$ vs. $54 \%$ and $37 \%$ vs. $76 \%$ respectively. 


\section{Chapter V: Discussion}

\section{Discussion}

Prior to the initiation of Reducing the Risk, this school did not have a sexual education program. During health classes the topics of relationships and sexually transmitted infections were discussed minimally. This intervention was a change to the curriculum. It allowed the students to receive a deeper understanding of sexual behavior and the associated risks, taught by a trained health professional.

This project suggests a comprehensive sexual education program can be effective at increasing self-efficacy and the knowledge of risks associated with sexual activity among high school students in Baltimore. The use of role playing that focused on appropriate dialogue to say no, delay intercourse and discuss contraception assisted in the increase of scores on the posttest. It was evident at the beginning of the project; the knowledge of risks associated with sexual intercourse and the most effective methods of prevention was minimal and incorrect in many instances. Initially, there were challenges in delivering the information to the students as there was need for constant repetition to dispel inaccurate beliefs regarding STI prevention that were held by the students. Weekly discussions regarding appropriate methods of contraception, STI transmission and prevention of teen pregnancy contributed to the significant difference in scores. Review of the literature shows an increase in knowledge and self efficacy scores in other comprehensive sexual education programs (Roberto et al., 2007; Sulak, Herbelin, Fix \& Kuehl, 2006; Aarons, Jenkins, Raine, Korpi, Kirby, 2007).

Adhering to the Health Belief Model played an integral part in the program's success.

The obstacle of getting the students to believe they were at risk of getting and STI or becoming pregnant either due to lack of knowledge or inconsistent contraceptive use were overcome 
through persistent discussions and role plays of how easy a person can become infected or get pregnant. The seriousness of either of these was also discussed throughout the entire program. To assist in making the seriousness relatable, dialogue was had about what their parents might say and what would happen after a diagnosis of HIV or a positive pregnancy test. The perceived barriers of the negative outcomes of using contraception or abstaining from sexual intercourse were discussed. This included a conversation about the cost of condoms and other methods of contraception. To dispel the myths about the expense of contraception the students were charged to go into stores and price various methods of contraception. There were also discussions regarding locations to access condoms and birth control at little to no cost. These discussions assisted the students in viewing the perceived benefits versus the barriers. The program provided numerous scenarios that placed the student in circumstances where they must choose to either abstain or use contraceptives. It also provided them with ways to say no and discuss contraceptive use with their partners. These cues to action allowed the students to recognize potentially dangerous situations and it provided them with appropriate methods to make the right decisions.

However, no change in behavior was noted as there was not an increase in the use of contraceptives. It is important to consider among the sample of participants that $71 \%$ were already sexually active at the onset of the intervention. Furthermore, among those who had engaged in sexual activity, the average age of initiation of intercourse was 15 years of age and the average number of partners was three, implying that the program was delivered later than what would better serve this student population. Initiation of this program in the freshman year, prior to the average age of initiation of intercourse may have increased the scores. The American College of Obstetricians and Gynecologists (ACOG) in a review of Reducing the Risk, reported 
amongst eighth and ninth graders who were not sexually active at the initiation of the program, there was a decrease in unprotected intercourse secondary to delayed onset of intercourse or increased use of condoms (2007). Moreover, for participants who were sexually inexperienced at the onset of the program, there was increased likelihood of contraceptive use (ACOG, 2007). Other programs aimed at increasing condom use were successful when the mean age of the participant was younger than this project (Jemmott et al., 2005; Aarons, Jenkins, Raine, Korpi, Kirby, 2007).

The faculty at the high school was enthusiastic about initiating the program and became fully vested in its success. They have requested the program continue and become a permanent part of the health curriculum. In addition to the program for the students, they would like a program for the parents of the students to foster communication about sexual activity, and support what the student is learning. Early in the intervention, it became evident the participants' knowledge of the male and female anatomy, basic health practices, contraception, and STI transmission and prevention was limited and that the knowledge had often been acquired from friends who held similar misconceptions. This knowledge deficit supports the need for sexual education to be afforded to the students earlier than their senior year of high school.

\section{Barriers}

There are limitations in this study. As mentioned, the majority of the participants had already engaged in intercourse with multiple partners. To improve contraceptive use and possibly delay the onset of intercourse, implementing the intervention in the freshman year, where the average age of students is 14 should be strongly considered. Moreover, the program should be expanded to include instruction on anatomy and physiology, hygiene and care of the

body. Repeated individual demonstration by the participants of appropriate condom application 
and more overall emphasis and focus on skills might have also assisted in increasing condom usage. Other limitations are related to the study itself. This research was completed using a quasi-experimental design. A controlled design with one group receiving the intervention and a comparison group receiving the standard health classes may have been a better measurement of the effectiveness of the program. The posttest was given six weeks after completion of the intervention. A longer up follow-up time might have allowed the student more time to change their behavior. Another factor that may be a limitation is the method of self-reporting. Although confidentiality and the importance of honesty were reiterated multiple times, self-reporting about sex and contraceptive use is a limitation.

\section{Conclusion}

This study provides evidence that a theory based comprehensive sexual education program can be effective in Baltimore City High Schools. There were statistically significant increases in both the knowledge survey and self-efficacy scores. Conversely, there was not a statistically significant change related to contraceptive use following the intervention. The expectation was an increase in condom use to prevent STI and pregnancy among those who were already sexually active. Based on other research studies with successful outcomes, future implementation of the program should begin earlier, in the freshman year. The average age of the freshman student is 14 and with the average age of onset of intercourse ranges between ages 15-17, the program would begin prior to the initiation of sexual intercourse. Furthermore, continuing the program throughout all four years of high school, with reiteration of perceived benefits and cues to action might assist with delay of sexual intercourse and/or increased contraception use. In addition to earlier implementation, the school might consider aligning themselves with the college clinic located across the street or with the Baltimore City Health 
Department. These resources would also provide the students with access to health education, contraception, and healthcare. Two high schools in two different cities initiated sexual education programs, one began a HIV/AIDS education program paired with condom distribution and the other linked a comprehensive sexual education program with a teen health center. A three year evaluation of both programs showed increased condom use (ACOG, 2007). The teen health center program also showed increased knowledge of correct condom use, pregnancy risk and various contraceptives (ACOG, 2007). Future research should assess the effectiveness of the evidence based program among other culturally diverse populations of adolescents. Prior to implementation the program should be amended to be culturally appropriate.

\section{Personal Goals}

My goal is to develop a comprehensive program aimed at building self-esteem and knowledge to effectively reduce the number of STIs and pregnancies amongst preteens and teens attending Baltimore City schools. The program would begin in junior high school. Earlier implementation of the program would introduce the risks associated with risky sexual behavior and the benefits of delaying intercourse or using contraception with each sexual act at a younger age. Implementation and evaluation of this intervention provided me with experience and knowledge of comprehensive sexual education. It also gave me insight to the importance of buy in from the stakeholders and the knowledge deficits among the students. As a result of this project I have been asked by the high school to implement a program that begins in the freshman year. This is in direct alignment with my aspirations. 
Appendix A. Approval of implementation of intervention dated March 28, 2012.

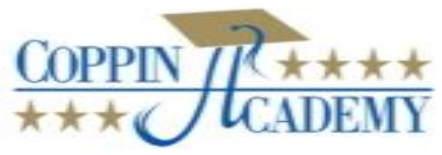

2500 W. North Avenue

Baltimore, MD 21216

(410) 951-2602

March 28, 2012

Darlene V. Hinds RN, MSN, CRNP, FNP-BC

Assistant Professor

Coppin State University

Helene Fuld School of Nursing

2500 W. North Avenue

Baltimore, MD 21216

(410) 951-6137

DHinds@coppin.edu

Dear Ms. Hinds:

Coppin Academy is pleased to support your Capstone Project entitled: Is comprehensive sexual education an effective method in increasing self-efficacy, increasing the knowledge of risks associated with intercourse, and increasing the use of contraceptives that decrease pregnancy and STI's among senior students attending a high school in Baltimore City? Given the increased incidences of teen pregnancy and Sexually Transmitted Infections in Baltimore City, we would welcome the opportunity to assist you in this project.

Please let me know how I, the faculty and staff can assist you in this very important project.

Sincerely,

Comed X. Cany

Ronnel L. Carey

Coppin Academy High School

2500 W. North Avenue

Baltimore, MD 21216

410-951-2602

rcarey@bcps.k12.md.us 
From: Peck, Marian R. [MRJohnson@bcps.k12.md.us]

Sent: Friday, November 09, 2012 2:15 PM

To: Hinds, Darlene

Subject: RE: Comprehensive Sexual Education Unit Confirmation

Good afternoon Ms. Hinds,

This email is to confirm that Coppin Academy is in support of the implementation of the

Comprehensive Sexual Education Unit . This unit will be part of the Health curriculum taught

during the second semester.

If you have any questions or concerns please contact me at 410-951-2600.

Thank you,

Mrs. Peck,

Interim Principal

Coppin Academy High School 
Appendix B. Approval to use Teen Attitude Pregnancy Scale.

From: Cheryl Leigh Somers [c.somers@wayne.edu]

Sent: Monday, March 19, 2012 1:12 PM

To: Hinds, Darlene

Subject: Re: Use of TAPS Request

Hi Darlene.

no cost. see attached. if you modify anything, please cite the original as you do that.

thanks! best wishes in your work!

cheryl

Cheryl L. Somers, Ph.D.

Associate Professor

Director, School \& Community Psychology Program Educational Psychology Dept.

345 College of Education, 5425 Gullen Mall Wayne State University Detroit, MI 48202

tel: $313-577-1670$

fax: 313-577-5235

c.somers@wayne.edu

http://tbf.coe.wayne.edu/

----- Original Message -----

From: "Darlene Hinds" <DHinds@coppin.edu>

To: "c somers" <c.somers@wayne.edu>

Sent: Monday, March 19, 2012 12:27:18 PM

Subject: Use of TAPS Request

Dr. Somers,

I am presently pursuing my Doctor of Nursing Practice degree at West Virginia University. In order to graduate, implementation of a Capstone project is required. My choice of project is a comprehensive sexual education program at a High School. Effectiveness of the program will be measured through use of a pretest and post test. Outcomes to be measured include increased knowledge of STIs and contraception, sexual self efficacy, consequences of teen pregnancy and a decrease in sexual behavior.

I am requesting use of the Teen Attitude Pregnancy Scale to effectively measure efficacy. Please let me know what steps I need to take including the cost of purchasing the tool.

Thank you in advance,

Darlene 
Appendix C. Tools

\section{TEEN ATTITUDE PREGNANCY SCALE (TAPS)}

Somers, C. L., Johnson, S. A., \& Sawilowsky, S. S. (2002). A measure for evaluating the effectiveness of teen pregnancy prevention programs. Psychology in the Schools, 39-3, 337-342.

\section{FUTURE ORIENTATION (1-4)}

$\begin{array}{llll}\text { strongly } & \text { not } & \text { strongly } \\ \text { disagree } & \text { disagree } & \text { sure } & \text { agree } \\ \text { agree }\end{array}$

1. Finishing high school is important to me.

2. Having a child as a teenager would make it harder for me to graduate from high school.

3. I am planning on furthering my education after high school.

4. Having a child as a teen would make it harder for me to further my education after high school.

\section{REALISM ABOUT CHILD REARING (5-8)}

5. If I or my girlfriend were pregnant, I would be able to care for my child without help from anyone else.

6. I am responsible enough to be a good parent now.

7. I am financially secure enough to be a good parent now.

8. I am emotionally mature enough to be a good parent now.
1

1

2

2

2

2

3

4

5

5

5

5

$4 \quad 5$

\section{5}




\section{SEXUAL SELF-EFFICACY (13-16)}

13. If you and your boyfriend/girlfriend wanted to have sex and you didn't have any birth control available, how sure are you that you would say "no" to avoid getting pregnant?

very unsure $\quad$ somewhat unsure $\quad$ undecided $\quad$ somewhat sure $\quad$ very sure

14. How sure are you that if you had sex you would always use birth control?

very unsure $\quad$ somewhat unsure $\quad$ undecided $\quad$ somewhat sure sure

15. How sure are you that you can wait to have sexual intercourse until you have graduated from high school?

very unsure $\quad$ somewhat unsure $\quad$ undecided somewhat sure $\quad$ very sure

16. How sure are you that you could say "no" to your boyfriend/girlfriend if he/she wanted to have sex and you didn't?

very unsure $\quad$ somewhat unsure $\quad$ undecided somewhat sure $\quad$ very sure

\section{Questions chosen from the Youth Risk Behavior Survey:}

17. Have you ever had sexual intercourse?
A. Yes
B. No

18. How old were you when you had sexual intercourse for the first time?

I have never had sexual intercourse

11 years old or younger

12 years old

13 years old

14 years old

15 years old

16 years old

17 years old or older 
19. During your life, with how many people have you had sexual intercourse? (19)

I have never had sexual intercourse

1. 1 person

2. 2 people

3. 3 people

4. 4 people

5. 5 people

6. 6 or more people

20. During the past 3 months, with how many people did you have sexual intercourse?

I have never had sexual intercourse

I have had sexual intercourse, but not during the past 3 months

1 person

2 people

3 people

4 people

5 people

6 or more people

21. Did you drink alcohol or use drugs before you had sexual intercourse the last time?

I have never had sexual intercourse

Yes

No 
22. The last time you had sexual intercourse, did you or your partner use a condom?

I have never had sexual intercourse

Yes

No

23. The last time you had sexual intercourse, what one method did you or your partner use to prevent pregnancy? (Select only one response.)

I have never had sexual intercourse

No method was used to prevent pregnancy

Birth control pills

Condoms

Depo-Provera (or any injectable birth control), Nuva Ring (or any birth control ring), Implanon (or any implant), or any IUD (24)

Withdrawal

Some other method

Not sure

Centers for Disease Control and Prevention. 2011 Youth Risk Behavior Survey. Available at: www.cdc.gov/yrbs. Accessed on March 14, 2012.

\section{Reducing the Risk - Knowledge Survey (24-43)}

Read each question carefully and mark the answer you think is the best response. These words are used in this survey: having sex, STD and HIV. For this survey,

- having sex means vaginal sexual intercourse.

- STD stands for sexually transmitted disease or diseases. Some examples of STD are herpes, gonorrhea, syphilis, chlamydia and genital warts. Sometimes these are referred to as sexually transmitted infections (STI).

- HIV stands for human immunodeficiency virus.

\section{True False}

1. Most high school $\bigcirc_{1}$
$\mathrm{O}_{2}$
Not sure

$\mathrm{O}_{3}$ 
students are having sex.

2. A woman is protected from

$\mathrm{O}_{1}$

$\mathrm{O}_{2}$

$\mathrm{O}_{3}$ pregnancy the day she begins taking the pill.

3. All STDs can be

$\mathrm{O}_{1}$

$\mathrm{O}_{2}$

$\mathrm{O}_{3}$ cured by taking medicine.

4. A person with an

$\mathrm{O}_{1}$

$\mathrm{O}_{2}$

$\mathrm{O}_{3}$ STD who looks and feels healthy cannot give the infection to others.

5. Some STDs put a $\bigcirc_{1}$

$\mathrm{O}_{2} \quad \mathrm{O}_{3}$ person at higher risk of getting infected with HIV.

6. About 1 out of 4 $\mathrm{O}_{2} \quad \mathrm{O}_{3}$ sexually active teenagers get an STD each year.

7. The best way to $\mathrm{O}_{1}$ $\mathrm{O}_{2}$ $\mathrm{O}_{3}$ use a condom is to leave some space at the tip for the sperm.

8. A condom should be completely unrolled before it is placed on the penis.

9. Most health clinics must have the permission of parents to test and 
treat people under

18 years old for an

STD (including

HIV).

10. Pregnant

$\mathrm{O}_{1}$

$\mathrm{O}_{2}$

$\mathrm{O}_{3}$

women who are

infected with HIV

can pass the virus

on to the baby

before it is born.

11. Can the

Yes

No

Not

following

behaviors put you

at risk for getting

HIV?

a. Sharing needles

for tattooing or

piercing

b. Having sex without $O$

a condom

c. Donating blood

$\mathrm{O}_{1}$

d. Using the same

$\mathrm{O}_{1}$ condom twice

e. Hugging

$\mathrm{O}_{1}$

$\mathrm{O}_{2}$

$\mathrm{O}_{2}$

$\mathrm{O}_{2}$

12. Which of the following methods

are effective if used correctly to protect people from STD (including HIV) and pregnancy?

a. Choosing not to have sex

(abstinence)

b. Using hormone based birth control (e.g., the pill, DepoProvera shot, patch, vaginal ring)
Protects from

Pregnancy \&

STD/HIV

Protects from Neither

$\mathrm{O}_{3}$

$\mathrm{O}_{3}$

$\mathrm{O}_{2}$

$\mathrm{O}_{3}$

$\mathrm{O}_{2}$

$\mathrm{O}_{3}$

$\mathrm{O}_{3}$

Protects from

sure

Pregnancy only
$\mathrm{O}_{2}$

$\mathrm{O}_{3}$

$\mathrm{O}_{1}$

$\mathrm{O}_{2}$
$\mathrm{O}_{3}$ 

c. Using latex
$\mathrm{O}_{1}$
$\mathrm{O}_{2}$
$\mathrm{O}_{3}$ condoms
d. Using withdrawal
$\mathrm{O}_{2}$
$\mathrm{O}_{3}$
e. Douching (washing $\bigcirc_{1}$ out the vagina)
$\begin{array}{ll}\mathrm{O}_{2} & \mathrm{O}_{3}\end{array}$

Citation: ETR Associates. 2010. Reducing the Risk Student Knowledge Survey (revised

9.22.10). Scotts Valley, CA: ETR Associates. (C) 2010 ETR Associates. All rights reserved 


\section{Figure 1. Explanation of Classes}

1. Prior to Class 1 Initiating Reducing the Risk

a. Ground Rules of honesty, respect and privacy were discussed.

b. The principle of every question is a good question.

c. The importance of taking role plays seriously.

2. Class 1A Abstinence, Sex and Protection: Pregnancy Prevention Emphasis Class 1B Abstinence, Sex and Protection: HIV Prevention Emphasis

a. Curriculum was introduced.

b. Pregnancy risk activity

c. Statistics and knowledge about teen pregnancy

d. Skit about pregnancy

e. Exercise about STD/HIV

3. Class 2 Abstinence: Not Having Sex

a. Statistics about how many teens are having sex

b. Discussion of reasons teens don't have sex

c. Skit focused on Communication, Relationship building and Planning statements

d. Workbook assignment - "What Abstinence Means to Me"

4. Class 3 Refusals

a. Role Play about ways to say no

b. Body Language and Facial Expressions that represent not wanting to have intercourse

c. Poster with 5 ways to say No displayed in classroom

d. Skit with demonstration of Effective and Ineffective ways to say no

5. Class 4 Using Refusal Skills

a. Using Refusal Skills in Different situations

b. Skit at a Party

6. Class 5 Delay Tactics

a. Introduction of Delay Tactics

b. Role Play of Delay Statements and Actions, Methods to Create Space, Ending Situations Quickly and Building Relationships.

c. Workbook Assignment of Refusal or Delay

7. Class 6 Avoiding High-Risk Situations

a. Red Alert and Yellow Alert - what signals an unprotected sex crisis

b. How to handle crisis situations 
8. Class 7 Getting and Using Protection-I

a. Myths and Truths

b. Poster of Birth Control Methods displayed

c. Discussion of different forms of birth control

d. Assignment to go to the store and price different condoms and contraceptive foam

9. Class 8 Getting and Using Protection-II

a. Information about Condoms

b. Condom Demonstration

c. Discussion of where condoms can be found and for how much

d. Workbook Assignment - "How will you avoid pregnancy"?

10. Class 9 Knowing and Talking About Protection: Skills Integration-I

a. Myths and Truths about Protection

b. Role Play about using condoms and contraception

11. Class 10 Skills Integration-II

a. Role play regarding avoidance of sex in different settings

12. Class 11 Skills Integration-III

a. Practice handling situations

b. Role Play

c. Workbook Assignment -“Time for a Condom".

13. Class 12 Preventing HIV and other STDs

a. Information and Statistics about HIV and other STDs

b. Workbook Assignment - "How HIV would change my life".

14. Class 13 HIV Risk Behaviors

a. Identification of risk behaviors

b. Poster displayed in class of no risk, some risk and risky behavior

15. Class 14 Implementing Protection from STD and Pregnancy

a. Workbook assignment discussing the steps to protection, preparing for protection and using protection

16. Class 15 Sticking with Abstinence and Protection

a. Review shopping for condoms form

b. Discuss doubts that make it harder and actions that counter doubts that make it harder to use abstinence or use protection. 
17. Class 16 Skills Integration - IV

a. Discuss How HIV changed my life

b. Role Play - being safe on the couch 
Table 1. Overall contraceptive use among sample of high school participants.

\begin{tabular}{|l|l|l|}
\hline Method & Pretest $\mathrm{n}=27$ & Posttest $\mathrm{n}=27$ \\
\hline No method was used to & $5 \%$ & $3 \%$ \\
prevent pregnancy & & \\
\hline Birth control pills & $0 \%$ & $5 \%$ \\
\hline Condoms & $3 \%$ & $11 \%$ \\
\hline $\begin{array}{l}\text { Depo-Provera (or any } \\
\text { injectable birth control), Nuva } \\
\text { Ring (or any birth control } \\
\text { ring), Implanon (or any }\end{array}$ & $13 \%$ & $5 \%$ \\
implant), or any IUD & $3 \%$ & $5 \%$ \\
\hline Withdrawal & & \\
\hline Some other method & $45 \%$ & \\
\hline Not sure & & \\
\hline & & \\
\hline
\end{tabular}


Table 2. Use of contraceptives among the sample of male and female high school students in Baltimore $(\mathbf{n}=27)$.

\begin{tabular}{|c|c|c|c|c|}
\hline Gender & $\begin{array}{l}\text { Intercours } \\
\mathrm{e}\end{array}$ & Method - Pretest & Method - Posttest & Partners \\
\hline Male & $\begin{array}{l}8 / 12- \\
66 \%\end{array}$ & $\begin{array}{l}\text { Withdrawal }-75 \% \\
\text { Condoms }-12.5 \% \\
\text { Not Sure }-12.5 \%\end{array}$ & $\begin{array}{l}\text { Withdrawal }-62.5 \% \\
\text { Condoms }-25 \% \\
\text { Depo Provera, Nuva } \\
\text { Ring, Implanon, IUD - } \\
12.5 \%\end{array}$ & 2 \\
\hline Female & $\begin{array}{l}19 / 26- \\
73 \%\end{array}$ & $\begin{array}{l}\text { Withdrawal - } 58 \% \\
\text { Depo Provera, Nuva } \\
\text { Ring, Implanon, IUD - } \\
26.3 \% \\
\text { No Method - } 10.5 \% \\
\text { Some other Method - } \\
5.2 \%\end{array}$ & $\begin{array}{l}\text { Withdrawal }-57.8 \% \\
\text { Condoms - } 10.5 \% \\
\text { Birth Control Pills - } \\
10.5 \% \\
\text { Depo Provera, Nuva } \\
\text { Ring, Implanon, IUD - } \\
5.2 \% \\
\text { Some other method - } \\
10.5 \% \\
\text { No method - } 5.2 \%\end{array}$ & 3 \\
\hline
\end{tabular}


Table 3. Pre-test and post-test scores using self-efficacy and knowledge tools before and after the educational intervention.

\begin{tabular}{|l|l|l|l|l|}
\hline & \multicolumn{1}{|c|}{ Pre test } & \multicolumn{1}{|c|}{ Post test } & t & Sig \\
\hline Self Efficacy & 13.37 & 16.51 & -4.913 & $<0.001$ \\
\hline Knowledge & 10.67 & 14.13 & -5.854 & $<0.001$ \\
\hline
\end{tabular}




\section{References}

American College of Obstetricians and Gynecologists (2007). Strategies for adolescent Pregnancy prevention. Retrieved June 29, 2013 from:

http://www.acog.org/ /media/Departments/Adolescent\%20Health\%20Care/StrategiesFor

\section{$\underline{\text { AdolescentPregnancyPrevention.pdf }}$}

Baltimore City Health Department (2010). Strategic plan to reduce teen births in Baltimore City. Retrieved March 26, 2011 from http://www.baltimorehealth.org/info/teen_preg_report_final.pdf

Center for Disease Control and Prevention (2004). Methodology of the youth risk behavior surveillance system. MMWR, 53 (No. RR-12). Retrieved from http://www.cdc.gov/mmwr/PDF/rr/rr5312.pdf

Center for Disease Control and Prevention (2008). Special focus profiles: STIs/STDs in adolescents and young adults. Atlanta, GA: U.S. Department of Health and Human Services, Centers for Disease Control and Prevention.

Center for Disease Control and Prevention (2009). 2009 sexually transmitted disease surveillance. Retrieved March 31, 2011 from http://www.cdc.gov/std/stats09/tables/10.htm

Center for Disease Control and Prevention (2010). Teenagers in the United States: Sexual activity, contraceptive use and childbearing. National Survey of Family Growth 20062008 (DHHS Publication No. 2011-1982). Retrieved March 30, 2011 from http://www.cdc.gov/nchs/data/series/sr_23/sr23_030.pdf

Center for Disease Control and Prevention (2010b). Youth Risk Behavior Surveillance SurveyUnited States, 2009. Morbidity and Mortality Weekly Report, 59, SS-5. Retrieved 
December 3, 2010 from http://www.cdc.gov/mmwr/pdf/ss/ss5905.pdf

Center for Disease Control and Prevention (2010c). Sexually Transmitted Disease

Surveillance 2009. Retrieved December 3, 2010 from

http://www.cdc.gov/std/stats09/surv2009-Complete.pdf

Center for Disease Control and Prevention (2011). HIV among youth. Retrieved

February 1, 2012 from www.cdc.gov/hiv/resources/factsheets/PDF/youth.pdf

Department of Health and Human Services - Office of Adolescent Health (2010).

Pregnancy prevention intervention implementation report. Retrieved January 30, 2011

from http://www.hhs.gov/ash/oah/oah-initiatives/tpp/programs/reducing the_risk.pdf

Dolcini, M., Harper, G., Boyer, C., Pollack, L. (2009). Project Ore: A friendship based

intervention to prevent HIV/STI in urban African American adolescent females. Health

Education and Behavior 37: 115

Downing-Matibag, T., \& Geisinger, B. (2009). Hooking up and sexual risk taking among college students: A health belief model perspective. Qualitative Health Research, 19, 1196.

ETR Associates (2010). Reducing the Risk Student Knowledge Survey (revised 9.22.10). Scotts Valley, CA: ETR Associates.

Gardner, M., \& Steinberg, L. (2005). Peer influence on risk taking, risk preference and risky decision making in adolescence and Adulthood: An experimental study. Developmental Psychology, 41(4), 625-635.

Guttmacher Institute (2010). U.S. Teenage Pregnancies, Births and Abortions: National and State Trends and Trends by Race and Ethnicity. Retrieved November 12, 2011 from: http://www.guttmacher.org/pubs/USTPtrends.pdf

Hall, K. (2012). The health belief model can guide modern contraceptive behavior research and 
practice. Journal of Midwifery \& Women's Health, 57, 74-81.

Hiltabiddle, S. (1996). Adolescent condom use, the health belief model, and the prevention of sexually transmitted disease. Journal of obstetrics, gynecology, and neonatal nursing, 25(1), 61-65.

Hubard, B., Giese, M., Rainey, J. (1998). A replication of reducing the risk, a theory based sexuality curriculum for adolescents. Journal of School Health 68(6), 243-247.

Jemmott, J., Jemmott, L., Braverman, P., Fong, T. (2005). HIV/STD risk reduction interventions for African American and Latino adolescent girls at an adolescent medicine clinic. Archive of Pediatric Adolescent Medicine 159, 440-449.

Jemmott, J., Jemmott, L., Fong, T., Morales, K. (2010). Effectiveness of an HIV/STD riskreduction intervention for adolescents when implemented by community-based organizations: A cluster randomized controlled trial. American Journal of Public Health $100,4$.

Kirby, D., Barth, N., Leland, N., Fetro, J. (1991). Reducing the risk: Impact of a new curriculum on sexual risk-raking. Family Planning Perspectives 23 (6), 253-263.

Maryland Department of Health and Mental Hygiene (2007). Maryland vital statistics annual report. Maryland Department of Health and Mental Hygiene 2007. Maryland vital statistics annual report. Retrieved February 20, 2010, from http://vsa.maryland.gov/doc/07annual.pdf

National Campaign to Prevent Teen and Unplanned Pregnancy (2010). Why it matters: Teen pregnancy. Retrieved December 3, 2010, from http://www.thenationalcampaign.org/why-it-matters/wim_teens.aspx

National Campaign to Prevent Teen and Unplanned Pregnancy (2011). Counting it up: 
The public cost of teen childbearing in Maryland in 2008. Retrieved March 30, 2012, from

http://www.thenationalcampaign.org/costs/pdf/counting-it-up/fact-sheet-maryland.pdf

Oringanje C., Meremikwu, M., Eko, H., Esu, E., Meremikwu, A., Ehiri J (2009). Interventions for preventing unintended pregnancies among adolescents. Cochrane Database of Systematic Review, 7(4).

Roberto, A., Zimmerman, R., Carlyle, K., Abner ,E., Cupp, P., Hansen, G. (2007). The effects of a computer-based pregnancy, STD, and HIV prevention intervention: a nine-school trial. Health Communication, 21(2) 115-124

Robin, L., Dittus, P., Whitaker, D., Crosby, R., Ethier, K., Mezoff, J., Miller, K., \& Pappas-Deluca, K (2004). Behavioral interventions to reduce incidence of HIV, STD, and pregnancy among adolescents: a decade in review. Health Education \& Behavior, $37(1), 115-32$.

Rosenstock, I., Strecher, V., Becker, M. (1988). Social learning theory and the health belief model. Health Education Quarterly, 15(2), 175-183.

Sexuality Information and Education Council of the United States (2004). Guidelines for comprehensive sexuality education. $3^{\text {rd }}$ Edition. Retrieved February 1, 2012 from http://www.siecus.org/_data/global/images/guidelines.pdf

Saunders, J. (2005). Adolescent pregnancy prevention programs: Theoretical models for effective program development. American Journal of Sexuality Education, 1(1), 63-84.

Somers, C., Johnson, S., \& Sawilowsky, S. (2002). A measure for evaluating the effectiveness of teen pregnancy prevention programs. Psychology in the Schools, 39-3, 337-342.

Sulak P., Herbelin S., Fix D., Kuehl T., (2006). Impact of an adolescent sex education 
program that was implemented by an academic medical center. American Journal of Obstetricians and Gynecologists, 195, 78-84

Zimmerman, R., Cupp, P., Donohew, L., Sinonean, C., Frist-Price, S., Helme, D. (2008). Effects of a school based, theory-driven HIV and pregnancy prevention curriculum. Perspectives on Sexual and Reproductive Health 40(1): 42-51. 